\title{
Building up Mathematical Modeling Using Spot Welding Parameters and Prediction Weld Nugget by Minitab
}

\author{
İlhan Çekiçi* ${ }^{*}$, Kadir Çavdar ${ }^{2}$ \\ 'Bursa Uludağ Üniversitesi, Mühendislik Fakültesi, Makine Mühendisliği Bölümü, 16059 Nilüfer Bursa. \\ ${ }^{2}$ Bursa Uludağ Üniversitesi, Fen Bilimleri Enstitüsü, Makine Mühendisliği Anabilim Dalı, 16059 Nilüfer Bursa
}

\begin{abstract}
In serial production, problems are constantly encountered in the selection of welding parameters due to the excess of welding parameters and variations. In order to compensate for these variations, mostly high energy flux is used. In this study, an approach developed in order to estimate weld nugget diameter in determining the welding parameters for sheets with a thickness of $0.6-3 \mathrm{~mm}$ is introduced. Sheet is an iron-based material that has been given certain mechanical and chemical properties in standards, turned into sheets from thick plates by rolling processes. Minitab statistical program was used to create experimental data and mathematical operations. First of all, 7 source parameters were selected and experimental study was carried out for 64 experiments using the $1 / 2$ partition factorial method of disegn of experiments(DOE) in Minitab software. With the experiments, real weld nugget diameters were obtained. These results were transferred to the Minitab software and the mathematical model of the system was established. Weld nugget diameter estimation procedures were carried out using the datas of factorical disegn of experiments(DOE). Test and prediction data were transferred to Minitab software, regression graph was drawn and R-Sq and R-Sq (adj) values were calculated. In addition, samples were created with randomly selected data for verification and comparison was made by transferring them to Minitab. According to the results of this study, remarkable accuracy rates have been achieved in the weld nugget diameter estimation with Minitab.
\end{abstract}

Keywords: Resistance spot welding, weld nugget prediction, design of experiment, regression analysis, Minitab.

\section{INTRODUCTION}

Today, 7-12 thousand spot welding is used when a car is being produced. Electric Resistance Welding (ERW) is generally done by computer controlled robots. The quality of ERW is an extremely important issue in the automotive industry. The accuracy and consistency of parameter settings made with manual welding parameter calculations, operator experience and technician expertise may not be appropriate.

Welding parameter setting of each machine and point is a difficult process due to many sensitive factors. It takes a lot of trials with a large number of materials to find the optimum value of each spot to be spot welded, which cannot be done as it is very costly. In order to achieve the final standard welding quality, different sheet thicknesses such as electrodes etc. The process of adjusting the parameters in each different welding machine model by changing it is quite costly. Therefore, in the ERW spot welding process, it is important to be able to meet the weld quality improvement requirements with efficiency estimation and appropriate parameter optimization.

When the literature is examined in general, it is seen that studies are carried out on a single sheet thickness by taking only the welding time, current and force. Different approaches can be seen for estimation methods.

In another method, welding current, electrode force and welding time other welding parameters can be kept constant. Welded joints can be subjected to tensile-shear tests to determine shear force and absorption energy values. In the study, parameter optimizations can be performed by using the surface methodology based on Box-Behnken design to generate a quadratic response model regression from Yue et al. [1].

There are also approaches to applying data mining techniques to estimate the weld nugget diameter in the ERW resource. With a relatively simple and straightforward approach, it can accurately estimate the diameter of a spot from easily measured signals during the welding process by Boersch $e t$ al. [2]. 
In addition, a real resource test dataset collected from the field can be predicted by using regression models such as a decision tree algorithm to extract decision rules. Here it can be seen that semantic rules are used to create accurate predictive models. With this method, allow engineers to reduce design and process alternatives response parameter (weld nugget width) can be effectively analyzed and predicted by Kim et al. [3].

There is a direct correlation between the selected parameters and the cooling rate and sheet thickness. It is an important factor in the formation of hardness values especially around the weld nugget region and weld nugget. It can be seen that the extreme hardness values negatively affect the rupture and weld nugget diameter values in the weld zone, which negatively affects the weld nugget diameter by Sheikhi et al., Kemda et al. $[4,12]$.

With samples created under variable welding currents I, electrode forces $\mathrm{F}$, welding times T, preheating currents IA, single-predictive optimization and spot break load estimation can be performed. Signal-to-Noise $(\mathrm{S} / \mathrm{N})$ ratio analysis and response surface modeling can be performed using RSM (response surface methodology) for optimization and prediction by Duric et al. [5].

In the other study, it is to present a prediction for the welded metal sheets characteristics as a result of varying parameters of resistance spot welding, also to predict the optimal welded material property for any given resistance spot welding parameters, besides, to foresee the probability of failure in the welding process before happening using simulation from the study of by Hiba et al., Hayat F. $[8,10]$.

A modified central compound design can be adopted to formulate an effective regression model that requires fewer experiments. The response surface methodology can be used to achieve optimum process conditions. Force current, welding time and welding force input variables, shear strength and spot crush amount can be output variables. By using TRIP steel, it is possible to obtain an optimum weld quality under relatively low welding currents and extending the welding time by Kim et al. [9].

Rather than using the result of a non-destructive testing technique as input variables, classifiers are trained directly with the relevant welding parameters, namely welding current, welding time and electrode type (electrode material and machining). Algorithms are compared for accuracy and area under receiver operating characteristic curve criteria using nested cross validation. Support vector machines using radial weld nugget, acceleration, and random forest techniques can generally achieve the best performance by Pereda et al. [11].

It also includes weld adhesion, the influence of weld parameters on joint quality, major metallurgical defects in $\mathrm{Al}$ spot welds, and electrode distortion. The contact resistance caused by the presence of an oxide layer on the surface of
Al alloys and the need for high current application due to Al alloys cause rapid electrode tip wear and inconsistency in welding quality. Cleaning the oxide layer and increasing the electrode strength and applying a low current preheating can significantly reduce the contact resistance and improve the connection quality from Manladan et al. [13].

In the studies presented in this article, unlike previous studies, a model was created by studying not only 3 parameters (current, force and time), but 7 parameters as used in mass production. In addition, in order to establish the ERW model in the most ideal conditions and accuracy, an experiment design was made and a statistically accurate model was formed. Verification tests are performed on the model whose accuracy is certain and the accuracy of the model has been clearly tested. The created model can also be used by researchers who want to do different studies.

In this study, as can be seen in the outputs of the test design study in the Minitab program, the effects of cooling time, approach and printing time have been tested with the test specimens shown in Fig. 1 by making 1/2-fraction test design in standard sizes, different sheet thicknesses. Afterwards, the mathematical model of the system was created.

After obtaining the model, the parameters were considered individually in the Minitab program and their correlation with the weldnugget diameter was examined. In addition, randomly selected parameters were applied in the field and real weld nugget diameters were found. These weld nugget diameters have been tried to be estimated with Y_predict in Minitab program. Then, the accuracy of the system was investigated by examining the regression of the field and predicted values and calculating the R-Sq and R-Sq (adj) values.

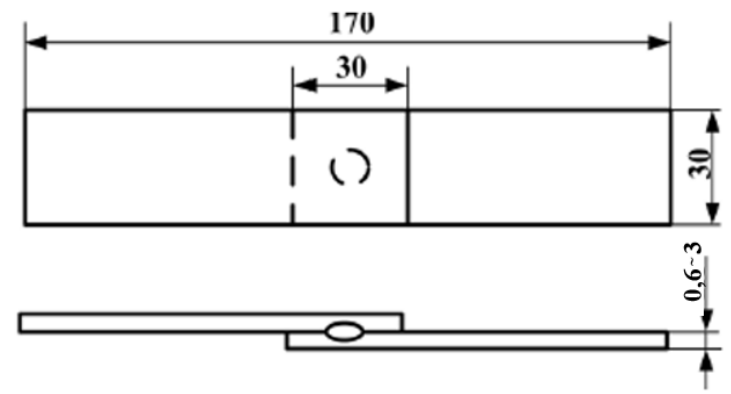

Figure 1. Welded specimen dimensions (in $\mathrm{mm}$ )

\section{MATERIAL AND METHOD}

The method used in the studies conducted in this section is summarized. In this research, ERW process was carried out under real conditions with a Unis Makina $100 \mathrm{kVA}$ and 100 $\mathrm{Hz}$ fixed spot welding machine. In this study, 0.6-3mm ref. sheet thicknesses were used according to the sheet thickness and parameters in the experimental design. These sheets, 6 and $8 \mathrm{~mm}$ diameter copper alloy tip were used in the experiments, see Fig. 2. Welding parameters, welding time, force, cooling, squence, holding and sheet thickness. and the weld nugget diameter output was investigated by using $1 / 2$ fraction experimental design. 


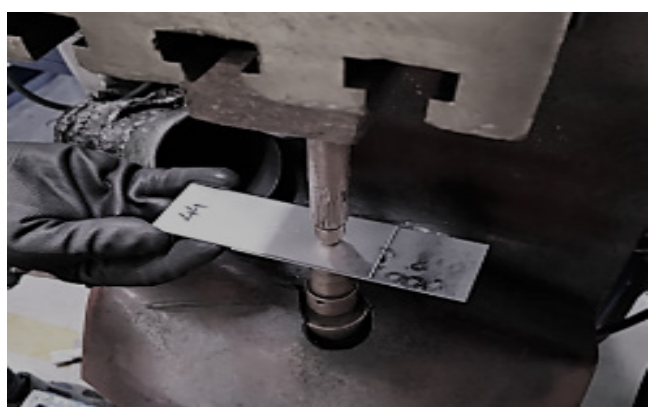

(a)

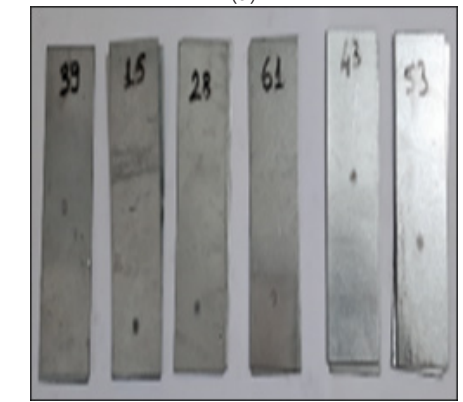

(b)

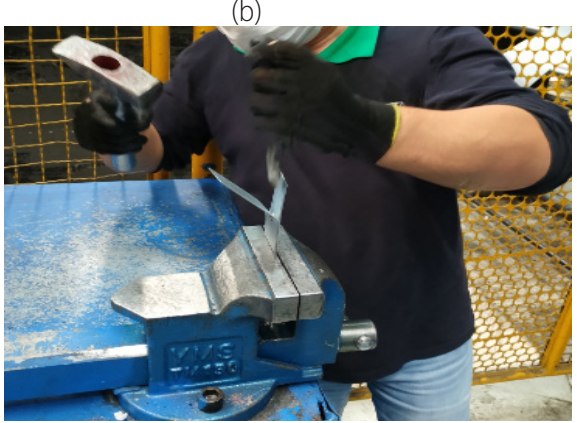

(c)

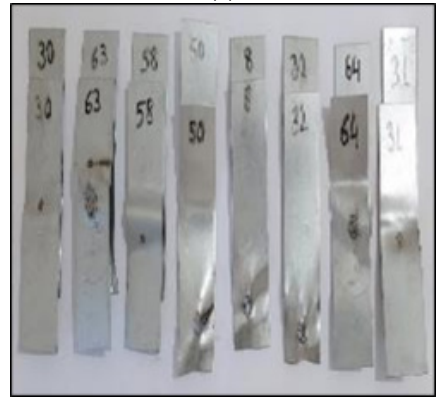

(d)

Figure 2. Application of experimental design data in the workshop (a) Welding application; (b,c,d) Teared down specimen

\subsection{Design of Experiment-DoE}

DoE is a systematic method for determining the relationship between factors affecting a process and the outcome of that process. In other words, it is used to find cause and effect relationships. This information is needed to manage process inputs to optimize output. In the design of the experiment, first of all the minimum and maximum values of each parameter are entered into the system. Then, what degree of experiment design will be done, that value is selected. The system is then asked to create the experiment design. The system randomly assigns each attempt to reflect the entire model.

In addition, Minitab 18 Statistical Software program was used in the studies. Here, an experimental design of 65 pa- rameters was created, with 64 and 1 center point (Fig. 3). The test was repeated with the same parameters in order to guarantee the accuracy of the parameters and weld nugget diameters obtained.

Although different sheet thicknesses are used experimentally in the study, the mechanical and chemical composition of only $0.8 \mathrm{~mm}$ sheet for simplicity is given in Table 1 and Table 2. These sheets are supplied by Erdemir company and their certificate number is 0031742Y and dated 18.3.2020.

\section{Fractional Factorial Design}

$\begin{array}{lrlrlr}\text { Design Summary } & & & & \\ \text { Factors: } & 7 \text { Base Design: } & 7 ; 64 & \text { Resolution: } \\ \text { Runs: } & 65 \text { VII } \\ \text { Blocks: } & 1 \text { Center pts (total): } & 1 & & \\ \end{array}$

Figure 3. Minitab parameters of experiment design

Table 1. Chemical structure of $0.8 \mathrm{~mm}$ thick specimen sheet

\begin{tabular}{|c|c|c|c|c|c|c|c|c|}
\hline \multicolumn{9}{|c|}{ FEE $220 \mathrm{BH}-\mathrm{ZNT} / \mathrm{F} / 2 \mathrm{~S}$ (ERDEMIR 0380) $-0.8 \mathrm{~mm}$} \\
\hline & $\% \mathrm{C}$ & $\% M n$ & $\% \mathrm{Si}$ & $\% \mathrm{P}$ & $\% \mathrm{~S}$ & $\% \mathrm{Al}$ & $\begin{array}{c}\% \mathrm{Ni}+\% \mathrm{Cu}+ \\
\% \mathrm{Cr}+\% \mathrm{Mo}\end{array}$ & $\begin{array}{c}\% \mathrm{C}+ \\
\% \mathrm{P}\end{array}$ \\
\hline$\% \min$ & 0.007 & 0.15 & & 0.05 & & 0.02 & \multirow{2}{*}{$\leq 0.5$} & \multirow{2}{*}{$\begin{array}{c}\leq \\
0.16\end{array}$} \\
\hline$\%$ maks & 0.06 & 0.7 & 0.5 & 0.09 & 0.03 & 0.07 & & \\
\hline
\end{tabular}

Table 2. Mechanical properties of $0.8 \mathrm{~mm}$ thick sheet

\begin{tabular}{|c|c|c|c|c|c|}
\hline \multicolumn{5}{|c|}{ FEE 220 BH-ZNT/F/2S (ERDEMIR 0380) } & $-0.8 \mathrm{~mm}$ \\
\hline Tensile Test & Tensile Strength (MPa) & Yield Strength (MPa) & \%Elongation \\
\hline Min:max & 305 & 400 & 200 & 270 & 34 \\
\hline
\end{tabular}

In Annex A, a part of the weld nugget diameters obtained as a result of the experiments carried out in the field, as opposed to the $1 / 2$ partition factorial input parameters obtained by the experimental design, are summarized.

It is seen in Annex B that the input parameters and their double-triple combinations are effective on the system. The values given here are the values obtained after applying backward elimination against the alpha value in the Minitab program.

\subsection{Backward Elimination}

It is a method for determining which variables to keep or not in a model. The backward elimination begins with the model containing all terms and then progressively removes the terms one by one using the same method. No variable can re-enter the model.

The probability value $P$ shows the amount of possible error we will make when we make the decision "there is a statistically significant difference" in a comparison. The maximum acceptable level of this error was suggested and accepted as 0.05 . If the $P$ value found in a test result is below 0.05 , it means that there is a significant difference as a result of the comparison.

Alpha number is the threshold value at which we meet $P$ values. Describes how excessively observed results should be to reject the null hypothesis of a significance test. The default backward elimination procedure ends when all of the variables included in the model are left with variables with a 
$P$ value greater than the value specified in Alpha.

\subsubsection{Stepwise Method}

Performs variable selection by adding or deleting predictors from the existing model based on the $F$-test. Stepwise is a combination of forward selection and backward elimination procedures. Stepwise selection does not proceed if the initial model uses all of the degrees of freedom.

\subsubsection{Variable to Remove}

Minitab calculates an $F$-statistic and $P$-value for each variable in the model. If the model contains $j$ variables, then $F$ for any variable, $x_{r}$, is this formula:

$$
F=\left(\left(\left(S S E_{\left(\left(j-X_{(r)}\right)\right)}-S S E_{j}\right) /\left(D F x_{r}\right)\right)\right) /\left(M S E_{j}\right)
$$

Here,

$$
\begin{aligned}
& \text { SS : Square of standard deviation } \\
& \text { MS : Square of means } \\
& S S E_{\left(\left(j-x_{(r)}\right)\right)}: \text { SS Error for the model that does not contain } x_{(r)} \\
& S S E_{j} \quad: \text { SS Error for the model that contains } x_{(r)} \\
& M S E_{j} x_{(r)}: \text { MS Error for the model that contains } x_{(r)}
\end{aligned}
$$

If the $P$-value for any variable is greater than the value specified in Alpha to remove, then Minitab removes the variable with the largest $\mathrm{p}$-value from the model, calculates the regression equation, displays the results, and initiates the next step.

\subsubsection{Variable to Add}

If Minitab cannot remove a variable, the procedure attempts to add a variable. Minitab calculates an F-statistic and p-value for each variable that is not in the model. If the model contains $j$ variables, then $F$ for any variable, $x_{a}$, is this formula:

$$
F=\left(\left(\left(S S E_{-} j-S S E_{-}\left(\left(j+X_{-} a\right)\right)\right) /\left(D F x_{-} a\right)\right) /\left(M S E_{-}\left(\left(j+X_{-} a\right)\right)\right)\right.
$$

$$
\begin{aligned}
& \text { DF : Degrees of freedom } \\
& S S E_{j}: \text { SS Error before } x_{a} \text { is added to the model } \\
& \operatorname{SSE}_{\left(\left(j+X_{a}\right)\right)}: \text { SS Error after } x_{a} \text { is added to the model } \\
& \operatorname{DFx}_{a}: \text { Degrees of freedom for variable } X_{a} \\
& \operatorname{MSE}_{\left(\left(j+X_{a}\right)\right)}: \text { MS Error after } x_{a} \text { is added to the model }
\end{aligned}
$$

If the $P$-value corresponding to the F-statistic for any variable is smaller than the value specified in Alpha to enter, Minitab adds the variable with the smallest $P$-value to the model, calculates the regression equation, displays the results, then goes to a new step. When no more variables can be entered into or removed from the model, the stepwise procedure ends.

By making Minitab \Stat $\backslash$ DOE $\backslash$ Factorial $\backslash$ AnalysiFactorialDesign \Stepwise \ backward elimination, the ideal probability coefficient $\mathrm{P}>0,05$ is automatically drawn in all input parameters. Here, resource time is the parameter with the greatest impact. As seen in Annex A, all parameters and their combinations affect the weld nugget diameter. Here; $\mathrm{S}$ $=0.0847054 \mathrm{R}-\mathrm{Sq}=99.53 \% \mathrm{R}-\mathrm{Sq}(\mathrm{adj})=96.69$ and the accuracy of the system is quite high. Welding current is the input parameter with the greatest impact on the entire system, cooling as a single parameter the least effective. The singular and percentage effects of the effects of the parameters are shown below, Figures 4 and 5 . Here, it is seen that the combinations of 2 and 3 of the parameters are much more effective instead of individual parameters. The values are given interactively in Fig. 6.

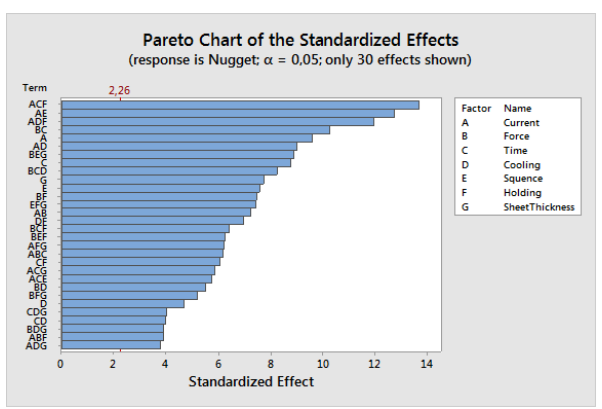

Figure 4. Standart effects of welding parametres

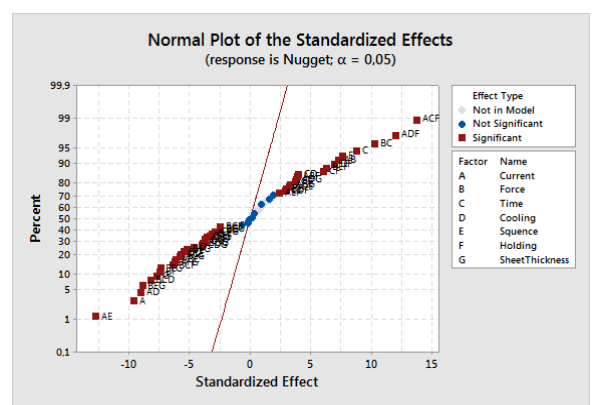

Figure 5. Percentage distribution of the effects of the weld parametres

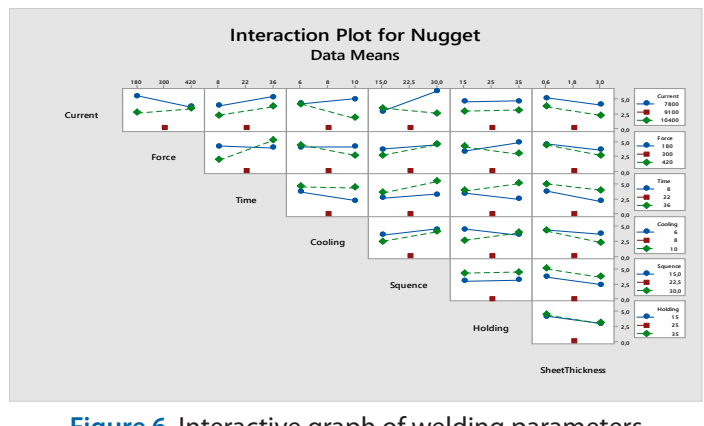

Figure 6. Interactive graph of welding parameters

In the Minitab, the mathematical model of the system was created as follows: 


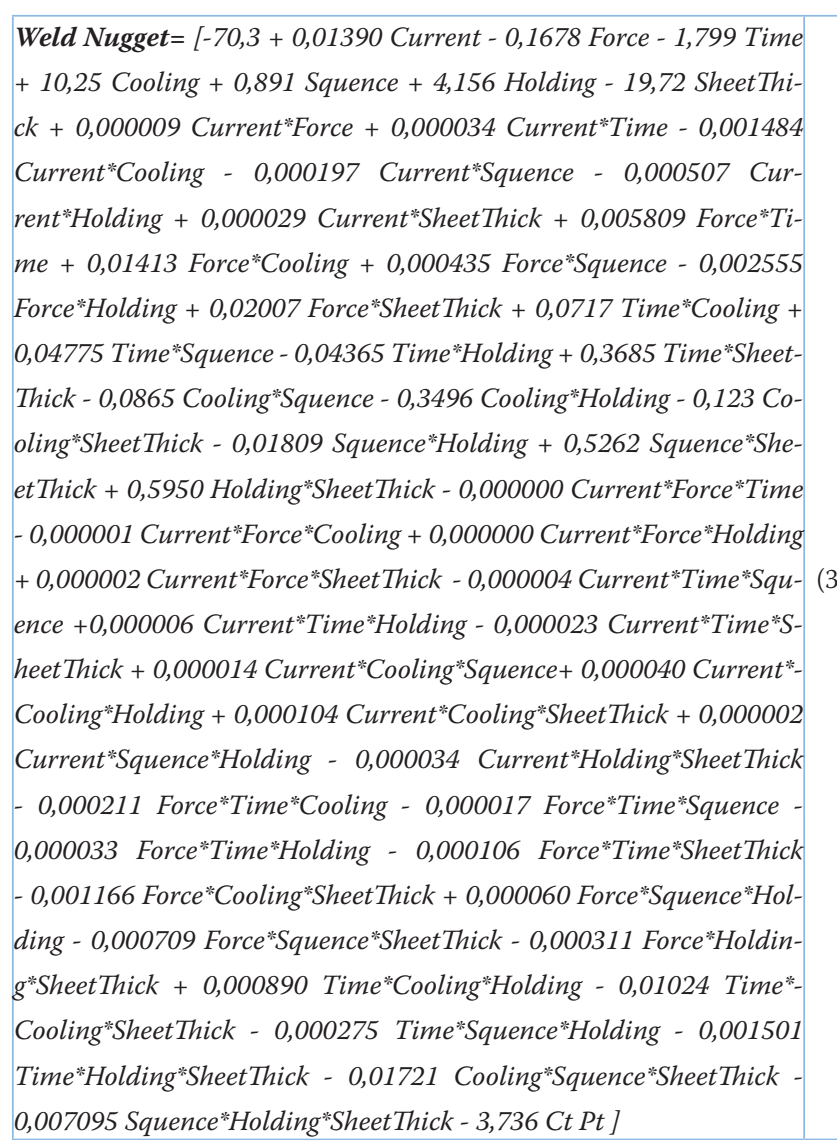

Optimal values were used at certain intervals when determining the electrical resistance welding (ERW) parameters, Table 3.

Table 3. Minimum and max values of spot welding parameters (for 0.6$3 \mathrm{~mm}$ sheets)

\begin{tabular}{|c|c|c|}
\hline Parameters & $\min$ & $\max$ \\
\hline Current (A) & 7800 & 10400 \\
\hline Force $($ daN) & 180 & 420 \\
\hline Time (cycle) & 8 & 36 \\
\hline Cooling (cycle) & 6 & 10 \\
\hline Squence $($ cycle) & 15 & 30 \\
\hline Holding $($ cycle) & 15 & 35 \\
\hline SheetThic $(\mathrm{mm})$ & 0,6 & 3 \\
\hline
\end{tabular}

\subsection{Methods and Formulas for Prediction}

While working here, the values of the weld nugget diameter in the model were estimated by increasing the values for each parameter from Minitab $\backslash$ Stat $\backslash$ DOE $\backslash$ Factorial $\backslash$ Predict into $[14,15,16]$.

\subsubsection{Fit}

The fitted equation is:

$$
\hat{\mathrm{y}} \cdot=b_{0}+b_{1 X 1}+\ldots+b_{k x k}
$$

$\hat{y} \quad$ : fitted response

$\mathrm{x}_{\mathrm{k}} \quad: \boldsymbol{k}^{\text {th }}$ term. Each term can be a single predictor, a polynomial term, or an interaction term

$\mathrm{b}_{\mathrm{k}} \quad$ : estimate of $k^{\text {th }}$ population regression coefficient

\subsubsection{Prediction interval}

$$
\hat{y} \pm t_{\left(1-\alpha \frac{1}{2}, n-p\right)} \times s(\text { Pred })
$$

Here

$$
\mathrm{s}(\text { Pred })=\sqrt{\mathrm{s}^{2}}\left(1+x_{0}\left(X^{\prime} X\right)^{-1} X_{0}\right.
$$

$\hat{\mathrm{y}} \quad$ : fitted response value for a given set of predictor values

a : level of significance

n : number of observations

$p \quad$ : new value of the predictor

$s^{2} \quad$ : mean square error

$X \quad$ : prediction matris

$X_{0} \quad$ : matrix of given predictor values

$x_{0} \quad:$ transpose of the new vector of predictor values

\subsubsection{Standard error of fitted value (SE Fit)}

The standard error of the fitted value in a regression model with one predictor is:

$$
\text { SE Fit } \left.=\sqrt{s^{2}\left[\frac{1}{n}\right.}+\frac{\left(x_{0}-\bar{x}\right)^{2}}{\sum\left(x_{i}-\bar{x}\right)^{2}}\right]
$$

The standard error of the fitted value in a regression model with more than one predictor is:

$$
\sqrt{s^{2}}\left(X_{0}^{\prime}\left(X^{\cdot} X\right)^{-1} X_{0}\right.
$$

$s^{2}$

$n \quad$ :number of observations

$x_{0} \quad$ :new value of the predictor

$\bar{x} \quad$ :mean of the predictor

$x_{i} \quad:$ ith predictor value

$x_{0} \quad$ : vector of values that produce the fitted values, one for each column in the design matrix, beginning with a 1 for the constant term

$$
\begin{array}{ll}
x_{0} & : \text { transpose of the new vector of predictor values } \\
X & : \text { design matrix }
\end{array}
$$

\section{RESULTS}

Here some parameters affect the weld nugget diameter, which is the output data, with a positive correlation, some with a negative correlation. While a single parameter is increased, other parameters are kept at a constant min value. The interaction of the spot welding parameters with the weld nugget diameter is given in Figures 7-13.

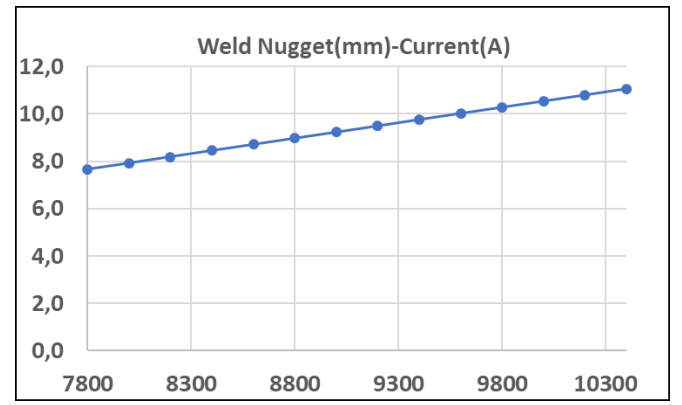

Figure 7. Weld nugget-current interaction 


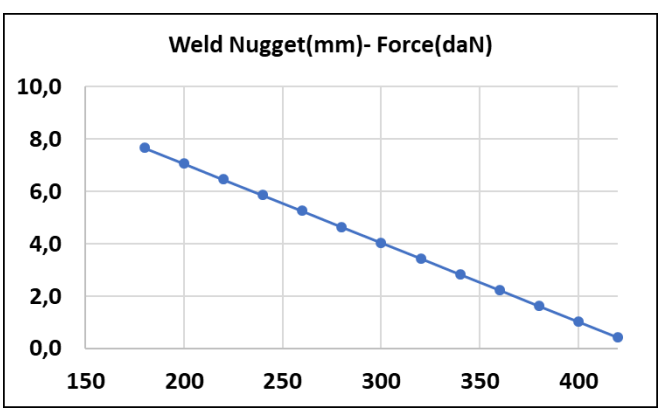

Figure 8 . Welding nugget-force interaction

In the figure 7 , it is seen that there is a positive correlation between current and nuget diameter. This situation is seen in the standardized effect graph that singularly, the current is a high factor. In the figure 8 , it is seen that there is a negatif correlation between the force and nugget diametre. This situation is seen in the standardized effect graph that singularly that the force is a not high factor.

In the figure 9 , it is seen that there is a negative correlation between the time and nugget diameter. This situation is seen in the standardized effect graph that singularly, the time is a secondary factor. For this mathematical model, the minimum of the other factors was chosen, resulting in a nugget diametre negative effect. In the figure 10 , it is seen that there is a negative correlation between the cooling and nugget diametre. This situation is seen in the standardized effect graph that singularly, the cooling is a very low impact factor.

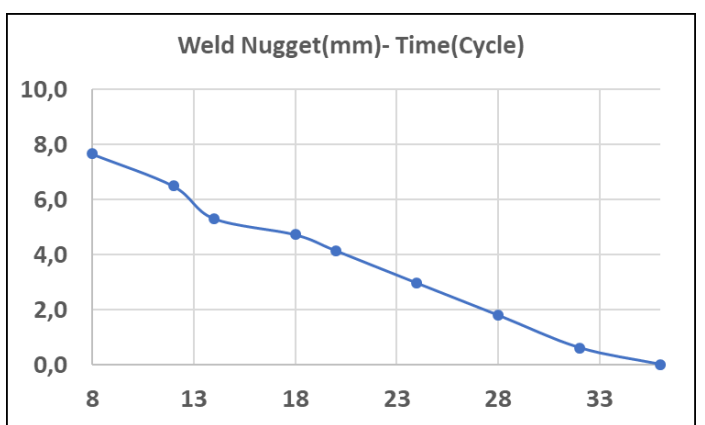

Figure 9. Weld nugget-time interaction

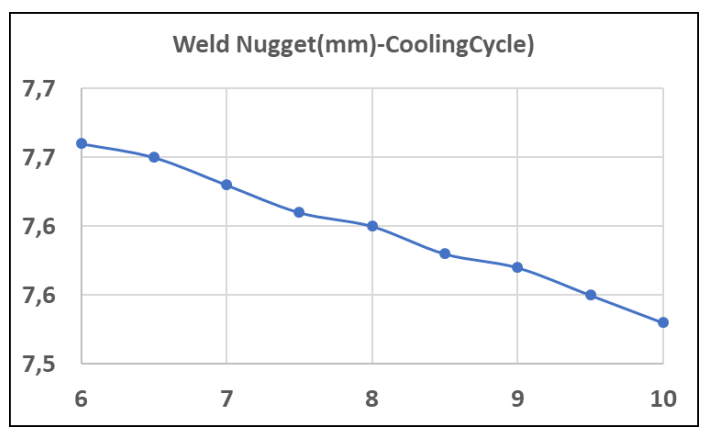

Figure 10. Weld nugget-cooling interaction

In the figure 11, it is seen that there is a negative correlation between the squence and nugget diametre. This situation is seen in the standardized effect graph that singularly, the squence is a secondary factor. For this mathematical model, the minimum of the other factors was chosen, resulting in a nugget diametre negative effect. In the figure 12 , it is seen that there is a positive correlation between the holding and nugget diametre. This situation is seen in the standardized effect graph that the holding is not a singularly factor. This factor acts on the system with the 2nd and 3rd combinations of other factors.

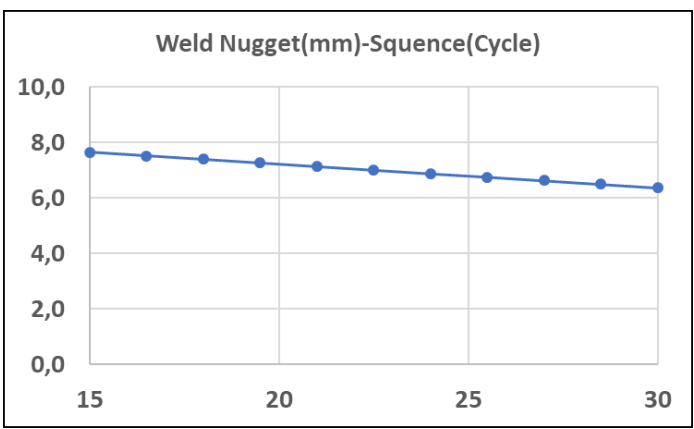

Figure 11. Weld nugget-squence interaction

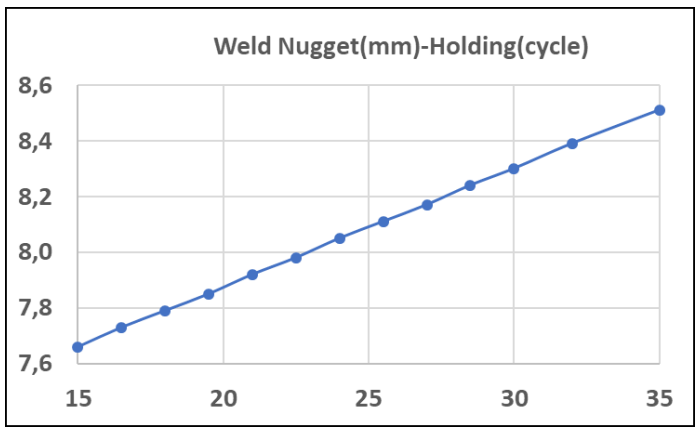

Figure 12. Weld nugget-holding interaction

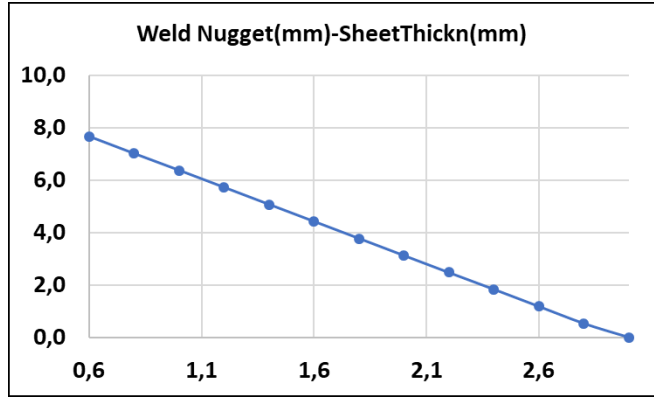

Figure 13. Weld nugget-sheet thickness interaction

In the figure 11, it is seen that there is a negative correlation between the sheet thickness and nugget diametre. This situation is seen in the standardized effect graph that singularly, sheet thickness is a secondary factor. For this mathematical model, the minimum of the other factors was chosen, resulting in a nugget diametre negative effect.

In addition, a study was conducted to test the accuracy of the model and randomly selected parameters were determined, see Table 4.

First of all, trial studies were made with randomly selected parameters in the field and the center diameter was measured. Y predict was made with the same parameters in the Minitab program and then regression analysis was applied by matching these values. The fitted line plot graph can be viewed graphically to view the relationship between a continuous predictive value and the opposite response. A linear, quadratic or cubic model can be selected for the data. A fitted line chart shows a scatter plot of the data with a regression line representing the regression equation. R2 or r2 and pronounced "R squared", is the proportion of the va- 
Table 4. Random sample parameters, weld nugget diameters and $Y$ predict values to verify

\begin{tabular}{|c|c|c|c|c|c|c|c|c|c|}
\hline $\begin{array}{c}\text { Blo- } \\
\text { cks }\end{array}$ & Current & Force & Time & $\begin{array}{c}\text { Coo- } \\
\text { ling }\end{array}$ & $\begin{array}{c}\text { Squen- } \\
\text { ce }\end{array}$ & Holding SheetT- & $\begin{array}{c}\text { Weld } \\
\text { hick }\end{array}$ & $\begin{array}{c}\text { Y pre- } \\
\text { dict }\end{array}$ \\
\hline 1 & 8800 & 180 & 25 & 10 & 25 & 20 & 1,5 & 4,74 & 4,5 \\
\hline 2 & 7800 & 180 & 15 & 6 & 30 & 15 & 1,5 & 5,63 & 5,79 \\
\hline 3 & 10400 & 180 & 36 & 10 & 20 & 35 & 1 & 7,49 & 9,29 \\
\hline 4 & 7800 & 180 & 20 & 10 & 25 & 15 & 1 & 6,73 & 6,75 \\
\hline 5 & 7800 & 180 & 25 & 10 & 20 & 35 & 1 & 6,01 & 5,98 \\
\hline 6 & 9000 & 180 & 25 & 6 & 15 & 35 & 2,2 & 4,64 & 4,2 \\
\hline 7 & 10000 & 180 & 36 & 10 & 30 & 35 & 2,2 & 7,28 & 7,09 \\
\hline 8 & 10000 & 180 & 25 & 10 & 30 & 15 & 3 & 0,00 & 1,81 \\
\hline 9 & 10200 & 180 & 22 & 6 & 15 & 35 & 3 & 0,00 & 1,9 \\
\hline 10 & 7800 & 180 & 36 & 6 & 25 & 15 & 3 & 5,52 & 4,59 \\
\hline 11 & 7800 & 180 & 20 & 10 & 20 & 35 & 0,8 & 5,90 & 5,85 \\
\hline 12 & 10400 & 180 & 15 & 6 & 30 & 15 & 0,8 & 5,97 & 4,15 \\
\hline 13 & 7800 & 180 & 20 & 10 & 15 & 35 & 0,8 & 5,21 & 5,39 \\
\hline 14 & 10400 & 180 & 15 & 6 & 30 & 15 & 0,8 & 5,69 & 4,15 \\
\hline 15 & 7800 & 180 & 36 & 6 & 30 & 35 & 2,4 & 7,21 & 7,17 \\
\hline 16 & 7800 & 180 & 25 & 10 & 15 & 30 & 2,4 & 5,79 & 5,2 \\
\hline 17 & 10000 & 250 & 10 & 6 & 15 & 30 & 1,5 & 4,35 & 3,57 \\
\hline 18 & 10400 & 420 & 30 & 10 & 25 & 35 & 1 & 6,41 & 6,29 \\
\hline 19 & 10400 & 420 & 30 & 6 & 30 & 35 & 2,2 & 5,15 & 3,57 \\
\hline 20 & 10400 & 420 & 20 & 10 & 20 & 35 & 3 & 0,00 & 0,79 \\
\hline 21 & 9800 & 420 & 25 & 10 & 25 & 15 & 2,4 & 0,00 & 0,76 \\
\hline 22 & 7800 & 420 & 36 & 6 & 15 & 15 & 2,4 & 5,65 & 5,58 \\
\hline 23 & 10400 & 420 & 36 & 6 & 15 & 35 & 2,4 & 6,12 & 6 \\
\hline & & & & & & & & & \\
\hline
\end{tabular}

riance in the dependent variable that is predictable from the independent variable(s). The adjusted R-squared is a modified version of R-squared that has been adjusted for the number of predictors in the model. In this study, RSq 91,7 and $\mathrm{R} \mathrm{Sq}$ (adj) 91,4, which show a very high accuracy rate. [14].

Here, the most suitable model was found to be the cubic model as a result of experiments.

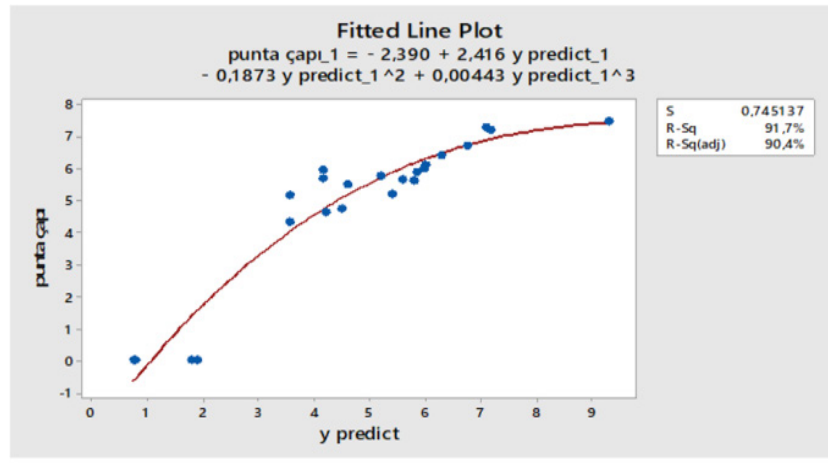

Figure 14. Regression plot of Minitab Y predict values with trial results

\section{CONCLUSION}

In solving current problems in the industry, math-based statistics programs are able to provide fast solutions, especially in the automotive sector. The statistical solutions of the Minitab program can be easily utilized in order to have more system inputs in the spot welding process and to obtain the optimum parameter.

Here, in determining the welding parameters, instead of determining the appropriate parameter by making many trials that will create high costs, statistics based Minitab program was used. Following the experimental studies summarized above, it is possible to make the following inferences:

- Some of the weld parameters have a positive correlation for the spot diameter, while some have a negative correlation.

- According to this mathematical model, while the current value (A) and the pressure value (cycle) have a positive correlation; It has a negative correlation with force value (daN), time (cycle), cooling (cycle) and sheet thickness.

- In the last study, a high R-Sq and R-Sq (adj) values were obtained with randomly selected parameters, which gives information about the mathematical model accuracy we obtained.

- In general, in order to make long trials in parameter determination and / or to avoid problems in mass production, unnecessary costs are created by giving higher energy than necessary.

As a result; According to the results of the experimental studies summarized in this publication, it is possible to determine the spot welding parameters, which is done with a lot of trial and error, especially in the automotive sector, by entering the attached parameters in a statistical program, creating a mathematical model only once, and continuously. In this case, optimum parameters with much higher accuracy can be easily selected without unnecessary time and cost of trial parts.

With the DOE set of the design of experiments (DOE) in the Minitab, the effect of source welding nugget diameter parameter inputs was digitized and a mathematical model was created for the outputs of the study result.

\section{REFERENCES}

[1] Yue, X. K., Tong, G. Q., Chen, F., Ma, X.L., Gao, X. P. (2016). Optimal welding parameters for small-scale resistance spot welding with response surface methodology. Institute of Materials, Minerals and Mining, 22(2):1-7. Doi: 10.1080/13621718.2016.1204799.

[2] Boersch, I., Füssel, U., Gresch, C., Großmann, C., Hoffmann, B.(2018). A non-destructive method to predict the welding spot diameter by monitoring process parameters. The International Journal of Advanced Manufacturing Technology, 99:1085-1099. Doi: 10.1007/ s00170-016-9847-y.

[3] Kim, K.Y., Ahmed, F.(2018). Semantic weldability prediction with RSW quality dataset and knowledge construction. Advanced Engineering Informatics, 38:41-53. Doi: org/10.1016/j.aei.2018.05.006.

[4] Sheikhi, M., Valaee, T.M., Fattah-Alhosseini, A., Usefifar, G.R. (2017). Thermal modeling of resistance spot welding and prediction of weld microstructure. Metallurgical and Materials Transactions A: Physical Metallurgy and Materials Science, 48(11):5415-5423. Doi: 10.1007/s11661-017-4314-4.

[5] Duric, A., Klobčar, D., Milčić, D., Marković, B. (2019). Parameter optimisation and failure load prediction of resistance spot welding of aluminium alloy 57547. Materials Science and Engineering, 659: 012042. Doi: 10.1088/1757-899X/659/1/012042. 
[6] Satonaka, S., Kaieda, K., Okamoto, S. (2004). Prediction of tensile-shear strength of spot welds based on fracture modes. Welding in the World: The International Journal of Materials Joining, 48(56):39-45. Doi: org/10.1007/BF03266430.

[7] Hayat, F. (2011). The effects of the welding current on heat input, nugget geometry, and the mechanical and fractural properties of resistance spot welding on $\mathrm{Mg} / \mathrm{Al}$ dissimilar materials. Materials and Design, 32(4):2476-2484. Doi: org/10.1016/j.matdes.2010.11.015

[8] Kim, T., Park, H., Rhee, S. (2005). Optimization of welding parameters for resistance spot welding of TRIP steel with response surface methodology. Science and Technology of Welding and Joining, 43(21):4643-4657. Doi: 10.1080/00207540500137365.

[9] Hiba, K.H., Israa, R.S., Iman, A.Z. (2019). Prediction of spot welding parameters using fuzzy logic controlling. Eastern-European Journal of Enterprise Technologies, 5 (2):101. Doi: 10.15587/17294061.2019.172642.

[10] Pereda, M., Santos, J.I., Galán, J.M., Martín, Ó. (2015). Direct quality prediction in resistance spot welding process: Sensitivity, specificity and predictive accuracy comparative analysis. Science and Technology of Welding and Joining, 20(8):679-685. Doi: org/10.1179/13621 71815Y.0000000052.

[11] Kemda, B. V. F., Barka, N., Jahazi, M., Osmani, D. (2015). Modeling of phase transformation kinetics in resistance spot welding and investigation of effect of post weld heat treatment on weld microstructure. Metals and Materials International. Doi: org/10.1007/ s12540-019-00486-x.

[12] Manladan, S.M. , Yusof, F., Ramesh, S., Fadzil, M., Luo, Z., Ao, S. (2017). A review on resistance spot welding of aluminum alloys. Int J Adv Manuf Technol, 90, 605-634 Doi:10.1007/s00170-016-9225-9

[13] Url, <https://support.minitab.com/en-us/minitab/18/help-andhow-to/modeling statistics/regression/how-to/fit-regression-mo$\mathrm{del} /$ methods-and-formulas/stepwise/> (Access date: 02.10.2020).

[14] Url, <https://support.minitab.com/en-us/minitab/18/help-andhow-to/modeling-statistics/using-fitted-models/how-to/predict/ methods-and-formulas/methods-and-formulas/> (Access date: 5.11.2020).

[15] Url, <https://support.minitab.com/en-us/minitab/18/help-andhow-to/modeling statistics/regression/how-to/fitted-line-plot/before-you-start/overview/> (Acces date:15.11.2020). 
Annex A. $1 / 2$ Division factorial experimental data (selected)

\begin{tabular}{|c|c|c|c|c|c|c|c|c|c|c|c|}
\hline Std-Ordr & RunOrdr & CenterP & Blocks & Cur & Force & Time & Cooling & Squence & Holdding & SheetThickınl & Nugget \\
\hline 4 & 1 & 1 & 1 & 10400 & 420 & 8 & 6 & 15 & 15 & 3 & 0 \\
\hline 64 & 2 & 1 & 1 & 10400 & 420 & 36 & 10 & 30 & 35 & 3 & 9,44 \\
\hline 1 & 3 & 1 & 1 & 7800 & 180 & 8 & 6 & 15 & 15 & 3 & 0 \\
\hline 65 & 4 & 0 & 1 & 9100 & 300 & 22 & 8 & 22,5 & 25 & 1,8 & 8,2 \\
\hline 17 & 5 & 1 & 1 & 7800 & 180 & 8 & 6 & 30 & 15 & 0,6 & 4,81 \\
\hline 48 & 6 & 1 & 1 & 10400 & 420 & 36 & 10 & 15 & 35 & 0,6 & 5,61 \\
\hline 46 & 7 & 1 & 1 & 10400 & 180 & 36 & 10 & 15 & 35 & 3 & 8,36 \\
\hline 25 & 8 & 1 & 1 & 7800 & 180 & 8 & 10 & 30 & 15 & 3 & 0 \\
\hline 32 & 9 & 1 & 1 & 10400 & 420 & 36 & 10 & 30 & 15 & 0,6 & 7,64 \\
\hline 29 & 10 & 1 & 1 & 7800 & 180 & 36 & 10 & 30 & 15 & 0,6 & 2,93 \\
\hline 52 & 11 & 1 & 1 & 10400 & 420 & 8 & 6 & 30 & 35 & 3 & 0 \\
\hline 34 & 12 & 1 & 1 & 10400 & 180 & 8 & 6 & 15 & 35 & 3 & 0 \\
\hline 62 & 13 & 1 & 1 & 10400 & 180 & 36 & 10 & 30 & 35 & 0,6 & 6,09 \\
\hline 16 & 14 & 1 & 1 & 10400 & 420 & 36 & 10 & 15 & 15 & 3 & 11,08 \\
\hline 30 & 15 & 1 & 1 & 10400 & 180 & 36 & 10 & 30 & 15 & 3 & 8,96 \\
\hline 9 & 16 & 1 & 1 & 7800 & 180 & 8 & 10 & 15 & 15 & 0,6 & 4,41 \\
\hline 57 & 17 & 1 & 1 & 7800 & 180 & 8 & 10 & 30 & 35 & 0,6 & 0 \\
\hline
\end{tabular}

Annex B. Input parameters and statistical impact analysis (backwise values)

\begin{tabular}{|c|c|c|c|c|c|c|c|c|c|c|c|}
\hline Welding & DF & Adj SS & Adj MS & F-Value & P-Value & Kaynak & DF & Adj SS & Adj MS & F-Value & P-Value \\
\hline Model & 55 & 911,341 & 16,5698 & 35,02 & 0 & Model & 55 & 911,34 & 16,5698 & 35,02 & 0 \\
\hline Lineer & 7 & 151,332 & 21,6189 & 45,69 & 0 & Lineer & 7 & 151,3 & 21,618 & 45,69 & 0 \\
\hline Current & 1 & 43,858 & 43,857 & 92,68 & 0 & 3-Yollu Etkileşim & 26 & 444,27 & 17,087 & 36,11 & 0 \\
\hline Force & 1 & 4,736 & 4,7361 & 10,01 & 0,011 & Current ${ }^{*}$ Force*Time & 1 & 17,925 & 17,92 & 37,88 & 0 \\
\hline Time & 1 & 36,512 & 36,5118 & 77,16 & 0 & Current*Force*Cooling & 1 & 6,598 & 6,598 & 13,94 & 0,005 \\
\hline Cooling & 1 & 10,288 & 10,288 & 21,74 & 0,001 & Current*Force*Holding & 1 & 7,203 & 7,202 & 15,22 & 0,004 \\
\hline Squence & 1 & 27,288 & 27,287 & 57,67 & 0 & Current*Force*SheetThick & 1 & 5,17 & 5,169 & 10,93 & 0,009 \\
\hline Holding & 1 & 0,375 & 0,3752 & 0,79 & 0,39 & Current*Time*Squence & 1 & 15,51 & 15,51 & 32,78 & 0 \\
\hline SheetThick & 1 & 28,27 & 28,27 & 59,75 & 0 & Current*Time*Holding & 1 & 88,97 & 88,97 & 188,02 & 0 \\
\hline 2-Way Interaction & 21 & 301,9 & 14,380 & 30,3 & 0 & Current*Time*SheetThick & 1 & 16,16 & 16,16 & 34,1 & 0 \\
\hline Current*Force & 1 & 24,713 & 24,713 & 52,23 & 0 & Current*Cooling*Squence & 1 & 4,824 & 4,8235 & 10,19 & 0,011 \\
\hline Current*Time & 1 & 0,006 & 0,0064 & 0,01 & 0,91 & Current ${ }^{*}$ Cooling*Holding & 1 & 67,692 & 67,6918 & 143,05 & 0 \\
\hline Current*Cooling & 1 & 38,688 & 38,688 & 81,76 & 0 & Current*Cooling*SheetThick & 1 & 6,786 & 6,786 & 14,34 & 0,004 \\
\hline Current*Squence & 1 & 76,891 & 76,891 & 162,49 & 0 & Current*Squence*Holding & 1 & 2,612 & 2,6123 & 5,52 & 0,043 \\
\hline Current*Holding & 1 & 0,047 & 0,047 & 0,1 & 0,75 & Current*Holding*SheetThick & 1 & 18,14 & 18,14 & 38,3 & 0 \\
\hline Current*SheetThick & 1 & 0,248 & 0,247 & 0,52 & 0,48 & Force ${ }^{*}$ Time $^{*}$ Cooling & 1 & 32,22 & 32,21 & 68,0 & 0 \\
\hline Force*Time & 1 & 49,93 & 49,93 & 105,5 & 0 & Force*Time*Squence & 1 & 2,873 & 2,873 & 6,07 & 0,03 \\
\hline Force*Cooling & 1 & 14,39 & 14,39 & 30,42 & 0 & Force*Time*Holding & 1 & 19,393 & 19,39 & 40,98 & 0 \\
\hline Force*Squence & 1 & 4,08 & 4,0804 & 8,62 & 0,017 & Force*Time*SheetThick & 1 & 2,928 & 2,928 & 6,19 & 0,035 \\
\hline Force*Holding & 1 & 26,458 & 26,4582 & 55,91 & 0 & Force ${ }^{*}$ Cooling*SheetThick & 1 & 7,216 & 7,215 & 15,25 & 0,004 \\
\hline Force*SheetThick & 1 & 3,041 & 3,040 & 6,43 & 0,032 & Force*Holding*Holding & 1 & 18,469 & 18,46 & 39,03 & 0 \\
\hline Time*Cooling & 1 & 7,439 & 7,439 & 15,72 & 0,003 & Force*Squence*SheetThick & 1 & 37,546 & 37,54 & 79,35 & 0 \\
\hline Time*Squence & 1 & 6,433 & 6,4326 & 13,59 & 0,005 & Force*Holding*SheetThick & 1 & 12,843 & 12,84 & 27,14 & 0,001 \\
\hline Time*Holding & 1 & 17,26 & 17,26 & 36,48 & 0 & Time*Cooling*Holding & 1 & 3,97 & 3,970 & 8,39 & 0,018 \\
\hline Time*SheetThick & 1 & 1,108 & 1,107 & 2,34 & 0,16 & Time*Cooling*SheetThick & 1 & 7,576 & 7,576 & 16,01 & 0,003 \\
\hline Soguma*Yaklas & 1 & 1,616 & 1,616 & 3,42 & 0,098 & Time*Squence*Holding & 1 & 5,319 & 5,318 & 11,24 & 0,008 \\
\hline Soguma*Holding & 1 & 22,84 & 22,84 & 48,29 & 0 & Time*Holding*SheetThick & 1 & 4,07 & 4,070 & 8,6 & 0,017 \\
\hline Cooling*SheetThick & 1 & 6,747 & 6,747 & 14,26 & 0,004 & Soguma*Holding*SheetThick & 1 & 6,144 & 6,144 & 12,98 & 0,006 \\
\hline Holding*Holding & 1 & 0,007 & 0,006 & 0,01 & 0,90 & Yaklaşm*Holding*SheetThick & 1 & 26,099 & 26,09 & 55,16 & 0 \\
\hline Holding*SheetThick & 1 & 0,014 & 0,013 & 0,03 & 0,87 & Eğrilik & 1 & 13,74 & 13,74 & 29,04 & 0 \\
\hline \multirow[t]{2}{*}{ Holding*SheetThick } & 1 & 0,024 & 0,024 & 0,05 & 0,82 & Error & 9 & 4,259 & 0,473 & & \\
\hline & & & & & & Total & 64 & 915,6 & & & \\
\hline
\end{tabular}

